\title{
ACTINOBACILOSE EM BOVINOS NO RIO GRANDE DO SUL
}

\author{
ACTINOBACILLOSIS IN CATTLE IN THE BRAZILIAN STATE OF RIO GRANDE DO SUL
}

\author{
Ademir José Mondadori ${ }^{1} \quad$ Franklin Riet-Correa ${ }^{2} \quad$ Gordon Robert Carter ${ }^{3}$ \\ Maria Del Carmen Mendez ${ }^{2}$
}

RESUMO

Realizou-se um estudo da distribuição geográfica e freqüência das lesర̃es diagnosticadas macroscopicamente como actinogranulomas, em bovinos abatidos em matadouros frigoríficos no Rio Grande do Sul, no período de 1980 a 1987. De um total de 7.326.902 bovinos abatidos durante esse período, $84.044(1,15 \%)$, apresentaram lesőes diagnosticadas macroscopicamente como actinogranuloma. Nåo foram observadas variaçőes importantes na prevalência anual de lesões e na prevalência nas microrregið̌es homogêneas do Estado. Amostras de 187 bovinos abatidos, com lesões semelhantes à actinobacilose foram coletadas para estudo histológico. De 159 animais que apresentaram lesões granulomatosas, foi diagnosticada actinobacilose em 131 (82,39\%); piogranuloma estafilocócico em $13(8,18 \%)$ e tuberculose em $15(9,43 \%)$. Em $28(17,61 \%)$ animais năo se observaram lesōes granulomatosas no estudo histológico. No estudo bacteriológico de 29 amostras isolaram-se Actinobacillus lignieresii em 19
$(65,52 \%)$ e staphylococcus aureus em 5 $(17,24 \%)$; nas 5 amostras restantes nåo houve crescimento bacteriano em ágar sangue. $O$ estudo histológico dessas lesర̃es confirmou o diagnóstico de actinobacilose e piogranuloma estafilocócico nas amostras em que foram isolados $A$. 1ignieresii e $S$. aureus, respectivamente. Nas amostras em que não houve crescimento bacteriano observaram-se lesőes características de tuberculose.

Palavras-chave: Actinobacilose, piogranuloma estafilocócico, actinogranulomas, bovinos.

\section{SUMMARY}

The geographical distribution and frequency of lesions grossly diagnosed as actinogranuloma were determined in cattle slaugthered in the State of Rio Grande do Sul, Brazil. Of 7.326.902 cattle slaugthered during 1980 to 1987, 84.044 (1.15\%) showed actinogranuloma-like lesions. No significant differences

\footnotetext{
${ }^{1}$ Médico Veterinário, MSc, Professor do Centro de Ciências Agroveterinárias, Universidade do Estado de Santa Catarina. Caixa Postal 281. 88520-000 Lages, SC, autor para correspondência.

${ }^{2}$ Médico Veterinário, MSc, Laboratório Regional de Diagnóstico, Universidade Federal de Pelotas, Faculdade de Veterinária. $96010-900$ Pelotas, RS.

${ }^{3}$ Médico Veterinário, DVM, MSc, DSc, College of Veterinary Medicine. Virginia-Marryland University. Virginia, USA.
} 
were detected in prevalence between years or among the different regions of the State. Specimens from 187 cattle with actinobacillosis-like lesions collected in three abattoirs, were studied histologically. On 159 cattle with granulomatous lesions, actinobacillosis was diagnosed in 181 (82.39\%), staphylococcic pyogranuloma in 13 $(8.18 \%)$ and tuberculosis in $15(9.43 \%)$. Granulomatous lesions were not observed in the histological sections of $28(17.61 \%)$ animals. Bacteriological examinations were performed on 29 samples. Actinobacillus lignieresii was isolated from $19(65.52 \%)$ and staphylococcus aureus from 5 (17.24\%). No bacteriological growth was obtained on blood agar from the other 5 specimens. The histological study confirmed the diagnosis of actinobacillosis and staphylococcic pyogranuloma from the A.Iignieresii and $s$. aureus positive samples, respectively. The 5 samples that were bacteriologically negative after 96 hours incubation were histologically diagnosed as tuberculosis.

Key words: Actinobacillosis, staphylococcic pyogranuloma, actinogranuloma, cattle.

\section{INTRODUÇÃO}

A actinobacilose dos bovinos é uma doença causada por Actinobacillus lignieresii, que afeta tecidos moles, causando piogranulomas com presença de drusas no seu interior.

No Brasil a actinobacilose foi mencionada pela primeira vez por Dacorso \& Azevedo apud FIGUEREDO et al. (1951) que, de 231.256 bovinos abatidos em um frigorífico de São Paulo, entre os anos de 1937 a 1940, diagnosticaram 33 casos da doença. Posteriormente FIGUEREDO et al. (1951), descreveram um caso de actinobacilose em Minas Gerais. No Rio Grande do Sul são descritos surtos da enfermidade afetando principalmente os linfonodos retrofaríngeos, parotídeos e submandibulares com uma morbidade variando entre $1 \%$ e $90 \%$ (RIET-CORREA et al., 1983; ALBUQUERQUE et al., 1983). Neste Estado WEISS \& SANTOS (1992), estudaram a presença de diferentes agentes em 254 linfonodos com granulomas actinomicóides provenientes de matadouros frigoríficos diagnosticando $154(60,6 \%)$ das lesões como botriomicose, $93(36,6 \%)$ como actinobacilose e $7(2,7 \%)$ como actinomicose.

Este trabalho objetivou determinar a freqüência e distribuição geográfica de lesões semelhantes a actinogranulomas encontradas em matadouros frigorífi- cos no Rio Grande do Sul, bem como os agentes causadores de lesర̃es macroscopicamente semelhantes à actinobacilose e estabelecer fatores epidemiológicos que determinam a ocorrência e freqüência da doença no Estado.

\section{MATERIAL E MÉTODOS}

Para determinar a prevalência de lesões diagnosticadas como actinogranulomas a nível de matadouros frigoríficos foi analisado o número de abates e respectivos índices anuais de carcaças apreendidas por essa causa, nos municípios do Estado do Rio Grande do Sul, no período de 1980 a 1987 (MINISTÉRIO DA AGRICULTURA, 1980/1987). Para o estudo realizado neste trabalho, o termo actinomicose, utilizado por esse Ministério, foi substituído pelo termo actinogranuloma e as lesర̃es observadas em matadouros frigoríficos suspeitas de serem actinobacilose, que podem ter sido causadas por diferentes agentes, são referidas como lesões semelhantes a actinobacilose. O termo piogranuloma estafilocócico é utilizado no lugar de botriomicose, actinofitose estafilocócica ou pseudomicose bacteriana utilizados por outros autores (WISLOW, 1959; WAISMAN, 1962; GREENBLATT et al., 1964).

$\mathrm{Na}$ amostragem dos materiais para estudo histológico adotou-se como critério básico a coleta de $10 \%$ da média de apreensăo anual de carcaças com lesర̋es sugestivas de actinogranuloma nos municípios da área de influência do Laboratório Regional de Diagnóstico (LRD), da Faculdade de Veterinária da Universidade Federal de Pelotas (UFPel), nos anos de 1980 a 1987. Fragmentos de linfonodo, língua, lábio, masseter e pulmão, foram coletados nos frigoríficos Extremo Sul S.A. e Casarin S.A. em Pelotas e Cicade S.A. em Bagé, RS, nos anos de 1987 e 1988 em um total de 187 bovinos. Os fragmentos eram fixados em formalina a $10 \%$, incluídos em parafina, laminados a $5 \mu$ e corados pelas técnicas de Hematoxilina-Eosina e de Gram pelo método de MacCallum-Goodpasture. As amostras negativas para drusas foram coradas pela técnica de Ziehi-Neelsen. Para o estudo bacteriológico, 29 amostras foram semeadas em ágar sangue ovino a $10 \%$ e incubadas a $37^{\circ} \mathrm{C}$ em aerobiose e microaerofilia. As 24 e 48 horas as colónias eram examinadas, submetidas a coloração de Gram e repicadas por esgotamento em Brain-Heart Infusion (BHI), Triple Sugar Iron (TSI) e ágar MacConkey. Também foram realizados testes bioquímicos de oxidase e catalase, determinação de urease, fermentação da glicose, redução de nitratos e observação da motilidade, 
produção de indol e ácido sulfídrico no meio de SIM. Três amostras foram testadas para a produçăo de acetil-metil carbinol (VP) e acidificação do vermelho de metila (VM).

O intervalo de confiança para estimar 0 percentual de lesðes causadas pelos diferentes agentes no período da amostragem, foi calculado pelo método descrito por SILVEIRA et al., (1980).

\section{RESULTADOS}

A prevalência anual de lesర̃es macroscopicamente semelhantes a actinogranuloma são apresentadas na Tabela 1. A prevalência por microrregiőes homogêneas apresenta-se na Figura 1. Na Tabela 2 apresenta-se o diagnóstico histológico das amostras de 159 bovinos com lesర̃es macroscopicamente semelhantes a actinobacilose, provenientes da área de influência do LRD. Foram diagnosticadas como actinobacilose as lesões caracterizadas histologicamente por piogranulomas com presença de drusas contendo cocobacilos Gram negativos no seu interior e como piogranuloma estafilocócico os piogranulomas contendo drusas com cocos Gram positivos. Em 28 bovinos năo foram observadas lesões granulomatosas. Na Tabela 3 são apresentadas as localizaçð̃es das lesð̃es granulomatosas diagnosticadas histologicamente em 159 animais.

Tabela 1 - Prevalencia anual de lesões macroscopicamente diagnosticadas como actinogranuloma, registradas pelo MINISTÉRIO DA AGRICULTURA no Estado do Rio Grande do Sul, no período de 1980-1987.

NÚMERO DE BOVINOS

\begin{tabular}{lrcr} 
ANO & ABATIDOS & $\begin{array}{c}\text { COM LESÕES SEMELHANTES A } \\
\text { ACTINO GRANULOMA }\end{array}$ \\
& & NÚMERO & PERCENTAGEM \\
& & & \\
\hline 1980 & 896.463 & 9.235 & 1,03 \\
1981 & 933.793 & 10.487 & 1,12 \\
1982 & 1.080 .047 & 10.438 & 0,97 \\
1983 & 1.050 .953 & 13.496 & 1,28 \\
1984 & 970.349 & 13.797 & 1,42 \\
1985 & 994.831 & 10.790 & 1,08 \\
1986 & 738.936 & 7.483 & 1,26 \\
1987 & 661.530 & 8.318 & 1,15 \\
& & & \\
\hline TOTAL & 7.326 .902 & 84.044 & \\
\hline
\end{tabular}

Fonte: Ministério da Agricultura (1980/1987)
Considerando que no período de 1986/1987, 15.801 bovinos abatidos apresentaram lesões semeIhantes a actinogranuloma, o percentual de lesర̃es actinogranulomatosas causadas pelos diferentes agentes na regiåo, durante esse período, pode ser estimado em $82,39 \% \pm 5,91 \%(P \leq 0,05)$ para actinobacilose $8,18 \% \pm 4,25 \%(P \leq 0,05)$ para piogranuloma estafilocócico e 9,43\% $\pm 4,53 \%(P \leq 0,05)$ para tuberculose.

No estudo bacteriológico das 29 amostras semeadas, foi isolado A. lignieresii em 19; $\boldsymbol{s}$. aureus em 5 e não houve crescimento até 96 horas de incubação nas 5 restantes. Todos os isolamentos de $A$. Iignieresii foram positivos para as provas de oxidase e catalase (algumas apresentaram reação fraca), fermentaram glicose sem produção de gás, não produziram $\mathrm{H}_{2} \mathrm{~S}$ nem indol; foram negativos para motilidade e VMNP, hidrolizaram uréia e cresceram em ágar MacConkey sem fermentar a glicose.

Todos os isolamentos classificados como $s$. aureus foram beta-hemolíticos, positivos para os testes de coagulase e catalase, negativos para a oxidase e fermentaram glicose sem produção de gás. O estudo histológico revelou que nas 19 amostras com crescimento de $\boldsymbol{A}$. 1ignieresii, em todas foram observados piogranulomas com presença de cocobacilos Gram negativos nas drusas. Nas 5 amostras de $\boldsymbol{s}$. aureus, foram observados piogranulomas com cocos Gram positivos nas drusas. As 5 amostras em que não houve crescimento bacteriano, apresentram lesões histológicas características de tuberculose.

\section{DISCUSSÃO}

No estudo bacteriológico de 29 amostras, em todos os materiais em que foi isolado Actinoba. cillus lignieresii tambem foram obsenados histologicamente piogranulomas com presença de drusas com cocobacilos Gram negativos no seu interior enquanto que os materiais nos quais foi isolado staphylococcus aureus apresentaram, no estudo histológico, drusas com presença de cocos Gram positivos no seu interior. Isso permite estabelecer a eficiência do estudo histológico mediante a coloração de Gram, utilizado nas amostras nas quais não se realizou estudo bacteriológico, para estabelecer 0 diagnóstico diferencial entre actinobacilose e piogranuloma estafilocócico. Outras lesões piogranulomatosas com formação de drusas no seu interior, causadas por Actinomyces pyogenes, Pseudomonas aeruginosa, Nocardia asteroides, streptococcus spp. (SHANAN \& DAVIS, 1942; GREENBLATT et al., 1964; KUBO et al., 1981/1982), que não foram observadas nesta amostragem, também podem ser diagnosticadas através das técnicas histológicas utilizadas neste trabalho. 



Figura 1 - Mapa mostrando a prevalencia ( $n^{\circ}$ decimais) de lesర̃es macroscopicamente semelhantes a actinogranuloma por microregiőes homogeneas em bovinos abatidos em matadouros frigorificos sob inspeçáo federal no Rio Grande do Sul no período $1980-1987$. 
Tabela 2 - Diagnóstico histopatológico de amostras de 159 bovinos com lesðes macroscópicas semelhantes a actinobacilose, nos municiplos da área de influencla do Laboratorio Regional de Diagnóstico (LRD), no período de 1987 - 1988

\begin{tabular}{lccc}
\hline MUNICIPIO & $\begin{array}{c}\text { ACTINO- } \\
\text { BACILOSE }\end{array}$ & $\begin{array}{c}\text { PIOGRANULOMA } \\
\text { ESTAFILOCÓCICO }\end{array}$ & $\begin{array}{c}\text { TUBER- } \\
\text { OLOSE }\end{array}$
\end{tabular}

\begin{tabular}{lccc}
\hline Arroio Grande & 15 & 2 & 4 \\
Bagé & 27 & 2 & 1 \\
Canguçú & 3 & 1 & 0 \\
Capáo do Leăo & 3 & 0 & 0 \\
Erval & 4 & 0 & 3 \\
Jaguarăo & 20 & 1 & 0 \\
Pedro Osório & 2 & 0 & 1 \\
Pelotas & 4 & 0 & 0 \\
Pinheiro Machado & 2 & 0 & 1 \\
Piratini & 5 & 3 & 0 \\
Rio Grande & 6 & 1 & 0 \\
Santa Vitoria & & 3 & 5 \\
do Palmar & 37 & 0 & 0 \\
Săo Lourenço & & & \\
do Sul & 3 & 13 & 15 \\
& & $8,8 \%$ & $9,43 \%$ \\
\hline TOTAL e & 131 & & \\
PERCENTAGEM & $82,3 \%$ & & \\
\end{tabular}

O resultado do estudo histológico das 159 amostras com lesões semelhantes a actinobacilose permite inferir que $82,39 \% \pm 5,91 \%(P \leq 0,05)$ das lesס̃es observadas em matadouros frigoríficos da região, no período da amostragem foram causadas por A. 1ignieresi i; 8,18\% $\pm 4,25 \%(P \leq 0,05)$ foram causadas por $s$. aureus e $9,43 \% \pm 4,53 \%(P \leq 0,05)$ foram devidas à tuberculose. É dificil estabelecer se as lesరes de actinobacilose observadas em matadouros frigoríficos correspondem a casos esporádicos da doença ou a animais provenientes de surtos, afetados subclinicamente ou recuperados parcialmente da doença clínica. Os dados de freqüência de actinobacilose observados neste trabalho, na área de influência do LRD, não podem ser extrapolados para outras regióes do Estado por que diferem dos encontrados por WEISS \& SANTOS (1992), que observaram que de 254 linfonodos provenientes de matadouros frigoríficos no Rio Grande do Sul, $60,63 \%$, foram diagnosticados como botriomicose; $36,62 \%$ como actinobacilose e 2,75\% como actinomicose.

Os dados do Ministério da Agricultura no período de 1980 a 1987, indicam que 1,15\%.dos animais abatidos a nível de matadouro frigorífico apresentam lesర̃es caracterizadas por actinogranulomas (Tabela 1), devendo ser incluidos nessa categoria a actinomicose e os granulomas semelhantes a actinobacilose. A actinomicose que nåo foi observada na amostragem para o estudo histologico, é aparentemente, uma doença pouco freqüente, o que está de acordo com os resultados obtidos por WEISS \& SANTOS (1992).

No LRD no período de 1978 a 1986 , foram diagnosticados 12 casos de actinobacilose, a maioria provenientes de surtos da doença, ocorridos em terneiros ou novilhos pastejando em resteva de arroz ou soja, com uma prevaléncia de $1,0 \%$ a $8,0 \%$. Dois desses surtos são descritos por RIET-CORREA et al., (1983). Por outro lado, ALBUQUERQUE et al., (1983) descreveram um surto em novilhos que afetou $90 \%$ dos animais. Em outros países, também, é relatada a ocorrência de surtos de actinobacilose, com prevalência variável entre $7 \%$ e $73 \%$ (HEBELER et al., 196i; CAMPBELL et al., 1975; NAKAZAWA et al., 1977).
Tabela 3 - Localização de lesões macroscopicamente semelhantes a actinobacilose, em 159 bovinos abatidos em matadou- ros frigoríficos da área de influencia do Laboratório Regional de Diagnóstico, no periodo de 1987-1988.

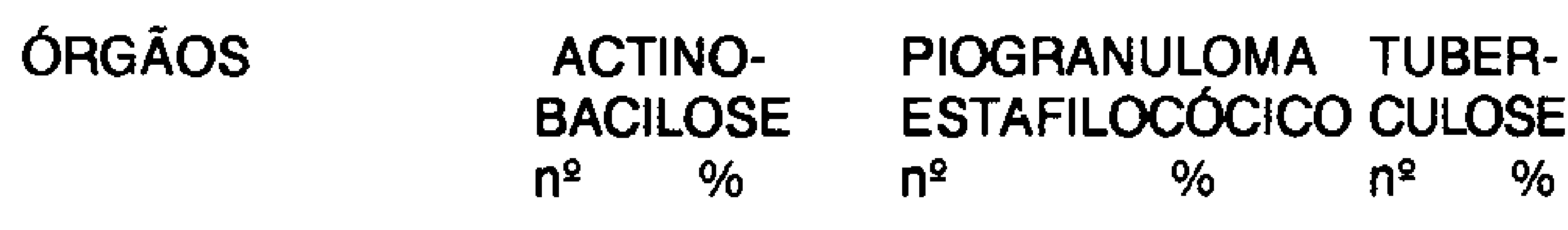

\begin{tabular}{|c|c|c|c|c|c|c|}
\hline \multicolumn{7}{|l|}{ Linfonodo } \\
\hline Submaxilar & 61 & 45,56 & 10 & 76,92 & 9 & $60, \infty$ \\
\hline Refrofaríngeo & 17 & 12,97 & 1 & 7,69 & 1 & 6,66 \\
\hline Pré-escapular & 2 & 1,52 & - & $\cdot$ & 2 & 13,33 \\
\hline Pré-crural & - & - & - & - & 1 & 6,66 \\
\hline Parotídeo & 5 & 3,81 & - & - & - & - \\
\hline Peitoral & 1 & 0,76 & - & - & - & - \\
\hline Mediastínicos & 1 & 0,76 & - & - & - & - \\
\hline Traqueo-brônquico & 1 & 0,76 & - & - & - & - \\
\hline Língua & 22 & 16,79 & 1 & 7,69 & 1 & 6,66 \\
\hline Lábio superior & 2 & 1,52 & - & - & - & - \\
\hline Lábio inferior & 5 & 3,81 & 1 & 7,69 & - & - \\
\hline Pulmāo & 1 & 0,76 & - & - & - & - \\
\hline Masseter & 1 & 0,76 & - & - & - & - \\
\hline \multicolumn{7}{|l|}{ Língua } \\
\hline L. retrofaríngeo & 1 & 0,76 & - & - & - & - \\
\hline Língua/L. submaxilar & 8 & 6,10 & - & - & - & - \\
\hline Lingua/L. parotideo & 1 & 0,76 & - & - & - & - \\
\hline \multicolumn{7}{|l|}{ Lábio inferior } \\
\hline $\begin{array}{l}\text { L.submaxilar } \\
\text { Pulmão }\end{array}$ & 2 & 1,52 & - & - & - & - \\
\hline L. mediastínicos & - & - & - & - & 1 & 6,66 \\
\hline TOTAL & 131 & 82,39 & 13 & 8,18 & 15 & 9,43 \\
\hline
\end{tabular}

$L=$ linfonodo. 
A. Iignieresii é um comensal do trato digestivo dos bovinos, produzindo a infecção quando existem soluçðes de continuidade na mucosa oral, que possibilitem a invasão do tecido pelo agente (PHILLIPS, 1961). Apesar de A. Iignieresii ser susceptivel às influências do meio ambiente, não sobrevivendo por mais de 5 dias no feno ou palha (TILL \& PALMER, 1960), a presença de animais com lesões supuradas, contaminando o meio ambiente, favoreceria a ocorrência da doença (CAMPBELL et al., 1975).

Pela obsenvação dos surtos de actinobacilose ocorridos na área de influência do LRD, pareceria existir uma relação entre pastejo de animais em restevas de arroz ou soja com a ocorrência da doença. Nessas áreas, a presença de forragem grosseira, devida a talos de arroz ou soja, que permanecem na área após a colheita ou a presença de plantas invasoras, poderia atuar como agente traumático na cavidade oral, favorecendo a infeç̧ão por $A$. Iignieresii. Apesar disso, os resultados obtidos no estudo da prevalência de lesões diagnosticadas em matadouros frigoríficos com actinogranuloma, nas diferentes microregiőes do Estado (Figura 1), não permitem estabelecer os fatores epidemiológicos que determinam a ocorrência e freqüência da doença no Rio Grande do Sul.

Apesar de que a forma clínica classicamente descrita da actinobacilose ser a forma lingual, é evidente que a mais freqüente nos surtos ocorridos no Estado é a forma que afeta principalmente os linfonodos retrofaríngeos, parotídeos e submandibulares. A forma lingual não foi observada nos surtos descritos por RIET-CORREA et al., (1983); ALBUQUERQUE et al., (1983).

Em surtos descritos em outros países a forma que acomete os linfonodos, também, é a mais freqüente (HEBELER et al., 1961; CAMPBELL et al., 1975; NAKAZAWA et al., 1977). Na amostragem realizada neste trabalho, também foi freqüente a forma que acomete linfonodos, já que do total de 131 animais com actinobacilose, 95 apresentavam-se nos linfonodos submandibulares, retrofaríngeos e parotídeos; 32 na língua e 9 nos lábios (Tabela 3).

Com relação ao piogranuloma estafilocócico, diagnosticado em $8,18 \%$ das lesర̃es macroscopicamente semelhantes à actinobacilose, é uma doença que ocorre em casos esporádicos, associado principalmente a contaminação de feridas (JONES \& HUNT, 1983). No Rio Grande do Sul não têm sido descritos surtos dessa doença, o que indica que os casos de piogranuloma estafilocócico, diagnosticados em matadouros frigoríficos, pertencem a animais afetados na forma subclínica, sem que ocorram perdas económicas significativas por causa dessa enfermidade.

\section{REFERÊNCIAS BIBLIOGRÁFICAS}

ALBUQUERQUE, A.J.D., BADCKE, M.R.T., BARCELOS, A.R., et al. Epizootia de actinobacilose em bovinos de abate. In: CONGRESSO ESTADUAL DE MEDICINA VETERINÁRIA, 1983. Porto Alegre, R.S. Anais ... Sociedade de Veterinária do Rio Grande do Sul, p. 60 .

CAMPBELL, S.G., WHITLOCK, R.H., TIMONEY, J.F., et al. An unusual epizootic of actinobacillosis in dairy heifers. J Am Vet Med Assoc, v. 166, n. 6, p. 604-606, 1975.

FIGUEREDO, J.B., HIPÓLITO, O., BARBOSA, M. Sobre um caso de infecção em bovino por Actinobacillus sp. Arq Esc Sup Vet Minas Gerais, v. 4, p. 52-56, 1951.

GARDET, J.P. Contribution a I"etude de l"actinomycose bovine. Lyon-France, 1980. 70 p. These ( ) - Ecole National de Lyon. no 32.1980.

GREENBLATT, M., HEREDIA, M., RUBENSTEIN, L., et al. Bacterial pseudomicosis (Botryomicosis). Am J Clin Pathol, v. 41, n. 2, p. 188-193, 1964.

HEBELER, H.F., LINTON, A.H., OSBORNE, A.D. Atypical actinobacillosis in a dairy herd. Vet Rec, v. 73, n. 21, p. 517-521, 1961.

JONES, T.C., HUNT, R.D. Veterinary Pathology. 5. ed. Philadelphia: Lea \& Febiger, 1983. Cap. 11: Deseases due to simple bacteria: p. 625-627.

KUBO, M., OSADA, M., KONNO, S. Morphology of sulfur granules produced by Pseudomonas aeruginosa in cows. Natl Inst Anim Health Q, v. 21, p. 26-31, 1981.

KUBO, M., OSADA, M., KONNO, S. Morphology of sulfur granules produced by staphylococcus aureus and Corynebacterium pyogenes in cows. Natl Inst Anim Helath Q, v. 22, p. 130-137, 1982.

MINISTÉRIO DA AGRICULTURA. Boletins Estatísticos de 1980 1987. Porto Alegre: Delegacia Federal de Africultura/RS. Serviço De Inspeção de Produto Animal/SERPA, 1987. Porto Alegre. RS.

NAKAZAWA, M., AZUMA, R., IAMASHITA, T., et al. Collective outbreaks of bovine actinobacillosis. Jap J Vet Sci, v. 39, p. 549-557, 1977.

PHILLIPS, J. The comensal role of Actinobacillus 1ignieresii. J Path Bact, v. 82, p. 205-208,1961.

RIET-CORREA, F., SCHILD, A.L., MENDEZ, M.C., et al. Relatório de atividades e doenças na área de influência no periodo de 1978-1982. Laboratório Regional de Diagnóstico (LRD), Universidade Federal de Pelotas (UFPel), Faculdade de Veterinária, Pelotas, RS. 1983 , p. 31.

SHAHAN, M.S., DAVIS, C.L. The diagnosis of actinomycosis and actinobacillosis. Am J Vet Res, v. 3, n. 9, p. 321-328, 1942.

SILVEIRA, P.J., ZONTA, E.P., SILVA, J.B., et al. Estatística geral inferência estatística. Pelotas: Universidade Federal de Pelotas, 1980. $156 \mathrm{p}$. 
TIIL, D.H., PALMER, F.P.A. A review of actinobacillosis with a study of the causal organism. Vet Rec, v. 72, n. 27, p. 527-543. 1960.

WAISMAN, M. Sthaphylococcic actinophytosis (botryomicosis) granular bacteriosis of the skin. Arch Dermatl, v. $86, n .4, p$ 525-529, 1962.
WEISS, R.D.N., SANTOS, M.N. Determinaçăo da etiologia de granulomas actinomicoides em bovinos no Rio Grande do Sul através da histoquímica. Pesq Vet Bras, v. 12, n. 3/4, p. 71-76, 1992.

WISLOW, D.J. Botryomicosis. Am J Pathol, v. 35, n. 1, p. 153-167, 1959. 